\title{
Em busca do indeterminado: Guimarães Rosa e seus tradutores
}

\section{Fernando Baião Viotti}

Resumo A partir da leitura de cartas de Guimarães Rosa aos seus tradutores, o artigo destaca a indeterminação de sentidos como recurso estético sugerido pelo escritor, tentando mostrar os modos e motivos peculiares que o orientavam. Em seguida - recorrendo a uma visada dialética - tal procedimento é confrontado com a busca pela precisão e exatidão, impulso diametralmente oposto, e também preconizado por Rosa na fatura das traduçōes. Palavras-chave Guimarães Rosa; correspondência; tradução; indeterminação; dialética.

Abstract Based on the letters written by Guimarães Rosa to his translators, this paper highlights the indetermination of meaning as an aesthetic resource of the author's. The objective is to show the peculiar ways and reasons that oriented him in this respect. The article also shows that the procedure is constantly and dialectically confronted by a search of correctness and precision, which is also advocated by Rosa in the making of his translations. Keywords Guimarães Rosa; letters; translation; indetermination; dialectic. 
Durante seus últimos dez anos de vida, João Guimarães Rosa correspondeu-se intensamente com os tradutores de suas obras para diversos idiomas. ${ }^{1}$ A leitura das cartas com os tradutores mostra que o escritor não apenas respondia com impressionante minúcia ao que lhe era questionado, como também detalhava espontaneamente significados ocultos das obras, desvendando nelas aquilo que chamava de seu sovrassenso: ou seja, o sentido metafísico que intencionalmente escondia sob uma descrição da natureza ou o nome de uma personagem. Nada mais nada menos do que uma explicação da essência de suas metáforas, por sua vez a essência de sua poética. Mais do que isso, Rosa apontava caminhos que acreditava serem os corretos para mimetizar nas línguas-alvo os efeitos buscados nos originais, dos quais um dos referidos mais frequentemente era o da indeterminação, conforme busco demonstrar a partir de algumas passagens da sua correspondência.

Em 1957, Antonio Candido publicou importante ensaio sobre Grande sertão: veredas. Nesse texto, intitulado "O homem dos avessos", em meio a numerosas considerações originais, o crítico propõe uma relação entre Grande sertão: veredas e Os sertōes de Euclides da Cunha:

Há em Grande sertão: veredas, como n'Os Sertões, três elementos estruturais que apoiam a composição: a terra, o homem, a luta. Uma obsessiva presença física do meio; uma sociedade cuja pauta e destino dependem dele; como resultado o conflito entre os homens. Mas a analogia para aí; não só porque a atitude euclidiana é constatar para explicar, e a de Guimarães Rosa inventar para sugerir, como porque a marcha de Euclides é lógica e sucessiva, enquanto a dele é uma trança constante dos três elementos, refugindo a qualquer naturalismo e levando, não à solução, mas à suspensão que marca a verdadeira obra de arte, e permite sua ressonância na imaginação e na sensibilidade. ${ }^{2}$ [grifos meus]

1 V. ROSA, João Guimarães; BIZZARRI, Edoardo. Correspondência com seu tradutor italiano Edoardo Bizzarri. Rio de Janeiro: Nova Fronteira, 2003; ROSA, João Guimarães; MEYER-CLASON, Curt. Correspondência com seu tradutor alemão Curt Meyer-Clason. Ed., Org. e Notas: Maria Apparecida Faria Marcondes Bussolotti. Rio de Janeiro: Nova Fronteira, 2003; VERLANGIERI, Iná Valéria Rodrigues. J. Guimarães Rosa - correspondência inédita com a tradutora norte-americana Harriet de Onis. Araraquara, 1993. Dissertação de mestrado - Universidade Estadual Paulista.

2 CANDIDO, Antonio. "O homem dos avessos". In: Tese e antitese. $4^{\mathrm{a}}$ ed. São Paulo: T. A. Queiroz, 2000, p. 123. 
Antonio Candido, ao propor as duas categorias - solução e suspensão - que estabeleceriam o antagonismo em meio à analogia entre Rosa e Euclides, toca, portanto, num procedimento central - para a criação da obra de arte em geral, como ele mesmo frisa - daquilo que seria uma "poética rosiana" (que o ficcionista de qualquer modo não deixou explícita em lugar nenhum): a opção pelo incerto, pelo obscuro, pelo indeterminado, que Guimarães Rosa busca de maneira peculiar e com finalidades específicas.

Algumas passagens das cartas apontam que - mais do que uma opção isolada - esse era um impulso deliberado. As pistas vão desde sugestões bastante simples do escritor em torno da tradução de trechos específicos até proposições de caráter geral sobre a sua obra ou sobre aquilo que ele próprio chama de sua Weltanschauung. ${ }^{3}$ Na carta de 2 de janeiro de 1964 ao tradutor italiano Edoardo Bizzarri, Rosa responde a um rol de dúvidas relativas ao conto "Buriti”. Um dos 43 itens enumerados pelo tradutor e respondidos pelo escritor é o que se segue:

[pergunta Bizzarri] A segunda mulher do Irvino é morena White, ou morena colored, ou é bom que não se saiba claramente?

[resposta de Rosa] Mais para morena clara. Talvez porém melhor deixar em suspenso. ${ }^{4}$

Meses depois, na importante carta de $\mathbf{1 6}$ de dezembro daquele ano, escrita por Rosa após a leitura do Corpo di Ballo finalizada há pouco por Bizzarri, aponta (depois dos hiperbólicos elogios ao trabalho do tradutor) três pequenos enganos, dentre os quais

um erro, mas do original ( $2^{\mathrm{a}}$ edição, pág. 145 [252, MM], linha 9 [5]): onde está "braçase-meias", devia ser "braças-e-meia" - como indeterminado, vago, mágico, algébrico ( $x$ braças $+1 / 2$ ), contrastando com o lógico, real, estricto, de "a menor, de 3 metros", i.e. "de três metros a menor" Mas não tem a mínima importância. ${ }^{5}$

3 O termo, que pode ser traduzido como "visāo de mundo" ou "concepção de mundo", foi explicado, dentre outros, por Benedito Nunes em sua Introduçāo à filosofia da arte (São Paulo: Desa, 1966, p. 139-141).

4 ROSA, João Guimarães; BIZZARRI, Edoardo. Op. cit., p. 116

5 Ibidem, p. 165.

324 • VIOTTI, Fernando Baião. Em busca do indeterminado: Guimarães Rosa... 
Aqui cabe um breve parêntese, para chamar a atenção à intervenção do diplomata Guimarães Rosa. Ainda que diga ao italiano que os erros "não têm a mínima importância", Rosa já escrevera um dia antes, em 15 de dezembro, outra carta ao tradutor alemão Curt Meyer-Clason, alertando-o dos erros cometidos por Bizzarri e reafirmando a correção do original e diretriz para a tradução de "braças-e-meia":

Creio que, quando aí estive, falamos sobre este ponto. Deve-se tomar o "braças-e-meia" como indeterminado. Sai-se do lógico, do real, ou do "aritmético" ("de três metros a menor") - para o vago, o indeterminado, o mágico, o "algébrico": "a maior, braças e meia!" = $\mathrm{x}$ braças $+1 / 2$ (ou: $\mathrm{x}$ braças $+1 / 2$ braça cada uma) ${ }^{6}$

Nesses dois exemplos, chama a atenção o cuidado do escritor para que não se perca nas traduções uma peculiaridade específica do texto original, que poderíamos marcar por meio de duas ideias derivadas das formulações do próprio escritor - suspensão e indeterminação - constituídas não apenas tomando-se o texto em seu todo, mas a partir de detalhes pontuais. Numa outra carta a Curt Meyer-Clason a busca da indeterminação é reafirmada, desta vez em termos mais abrangentes. Trata-se de comentário à tradução de "O recado do morro", que, em alemão, ganhou o título "Die Botschaft des Hüegels":

O PRIMEIRO PARÁgRAfo lucraria muito, a meu ver, se recebesse algumas importantes modificações. Trata-se de uma INTRODUÇão geral, que pretende ser concisa, enérgica, provocativa, "algébrica", sem denunciar o enredo do conto nem minimamente.

A) Assim, conviria, desde logo, eliminar aquele denunciador "Mordanschlag". в) о "nie" da primeira linha deve ser substituído por "nicht". c) o "gefürht gegen" deve ser: "geschehen um"; ou outro verbo, mas seguido de "um", e não de "gegen"; deve haver

6 A minúcia da explicaçāo reafirma o perfeccionismo de Rosa, já lembrado no decorrer deste trabalho. MeyerClason terá captado bem a questāo e o intuito de Rosa, pois, na carta seguinte, responde: "Os pontos mencionados casualmente não foram problema para mim: 'Siebzig und manchen Meter' ('Setenta e tantos metros'); e 'klafterlang und länger' ('muitas braças e bem mais') são nossos presentes para a poesia do 'indeterminado'.' ROSA, João Guimarães e MEYER-CLASON, Curt. Op. cit., p. 207 e p. 223. 
indeterminação, porque na minha Weltanschauung, as coisas "acontecem", ninguém "faz" nada, só pensa que faz.?

Além da menção direta à "indeterminação", trecho inclusive grifado pelo autor, a passagem trata de outra questão importante, a ser ao menos mencionada, ainda que sem profundidade. É o fato de o primeiro parágrafo do conto apresentar, segundo o autor, "uma introdução geral", revelando um procedimento adotado por Rosa com frequência. Na mesma carta ele dirá: “Trata-se de frase importante como todas as que iniciam as novelas; porque, como uma composição musical, têm de apresentar, de golpe, temas e motivos, e o tom dominante, com seus subtons". As frases iniciais dos contos teriam, pois, como acontece com as sinfonias, um caráter de ouverture, merecendo por isso atenção redobrada do tradutor. ${ }^{9}$

Uma outra questão suscitada é a afirmação incisiva do autor de que considerava a passagem como expressão de sua Weltanschauung, ideia reafirmada também em relação a "Buriti" e que pode parecer óbvia, mas não é, cabendo, nesse caso, uma série de questionamentos envolvendo os conceitos de intencionalidade autoral e o seu reflexo na fatura da obra, que são sempre relativos. Se ao fazer a afirmação o escritor deixa de fora esses questionamentos, isto não significa, entretanto, que em suas concepções estéticas considerasse a obra como retrato da própria visão de mundo, discussão que será retomada mais adiante.

7 Ao verificar o significado dos termos que Guimarães Rosa sugere, ficou clara sua intenção de conferir certa "vagueza" ao texto. "Mordanschlag" pode ser traduzido por "atentado", palavra que antecipa o que viria a ser o "caso de vida e de morte" do original. Outra oposição importante é entre "gegen" e "um". Enquanto o primeiro se traduz como "contrário", o segundo dá a ideia de "em torno", "em redor", conferindo o tom de imprecisão. Ibidem, p. 242.

8 Em outra carta ao alemão, Rosa lembra que o Grande sertão: veredas "como muito bem o viu o maior crítico literário brasileiro, Antonio Candido, obedece, em sua estrutura, a um rigor de desenvolvimento musical". Ibidem, p. 115 e p. 243.

9 Não resta dúvida de que essa peculiaridade na estruturaçăo formal dos contos - enfatizada pelo próprio autor - merece ser estudada mais a fundo. Na mesma carta ela é reafirmada também em relação a "Buriti": "A última frase do $1^{\circ}$ parágrafo não está exata. Rogo-Ihe meditá-la, traduzindo-a primeiro palavra por palavra, e refazendo-a. Contém, em resumo, toda uma Weltanschauung. se não uma concepção metafísica. (Cada palavra, nela, tem um valor rigoroso, insubstituível.) Não é o que Miguel pensa: é o que o autor diz. Houve uma mudança de plano". Ibidem, p. 245.

326 - VIOTTI Fernando Baião. Em busca do indeterminado: Guimarães Rosa... 
Antes é preciso lembrar que no âmbito do discurso epistolar ocorrem simplificações ou omissões, muitas vezes voluntárias, na medida em que entre os objetivos do missivista está a persuasão, o convencimento de seu interlocutor. Nessa passagem específica, o objetivo de Guimarães Rosa seria, portanto, chamar atenção para uma ideia central da novela, expressa no primeiro parágrafo, e que o escritor não queria que se perdesse na versão traduzida. Para entendê-la melhor vale recorrer ao texto literário, tentando analisá-lo em relação à explicação contida na carta a Meyer-Clason. Nela o escritor pede ao tradutor que não perca de vista uma especificidade importante do modo como se organiza o universo interno do conto, para que expresse uma especificidade da sua Weltanschauung: "as coisas 'acontecem', ninguém 'faz' nada, só pensa que faz". Para concretizar esse modelo peculiar de sucessão dos acontecimentos, o autor pede ao tradutor que recorra ao efeito da indeterminação, chegando inclusive a grifar a palavra.

Nesse caso, a indeterminação não é o objetivo final, mas um meio utilizado pelo escritor para compor concretamente no universo da obra uma visão abstrata sobre o ser e o seu estar no mundo, que, por enquanto, ainda não se sabe exatamente em que consiste. Mesmo a explicação que fornece ao tradutor é um tanto oblíqua, e parece interessante partir desta pouco elucidativa, mas fecunda proposição ("as coisas 'acontecem', ninguém 'faz' nada, só pensa que faz”), para analisar o parágrafo em questão, tentando surpreender no conto o tom de indeterminação tão caro ao autor:

Sem que bem se saiba, conseguiu-se rastrear pelo avesso um caso de vida e de morte, extraordinariamente comum, que se armou com o enxadeiro Pedro Orósio (também acudindo por Pedrão Chãbergo ou Pê-Boi, de alcunha), e teve aparente princípio e fim, num julho-agosto, nos fundos do município onde ele residia, em sua raia noroesteã, para dizer com rigor. ${ }^{10}$

Outros trechos que busquei destacar anteriormente, como a explicação em torno de "braças-e-meia", já fornecem a pista para entender aonde Rosa quer chegar. No

10 ROSA, João Guimarães. O recado do morro. In: No Urubuquaquá, no Pinhém. $7^{\mathrm{a}}$ ed. Rio de Janeiro: Nova Fronteira, 1984, p. 11. 
parágrafo acima, numa rápida leitura já se observam expressões decisivas para compor o tom de indeterminação: "sem que bem se saiba"; "rastrear pelo avesso"; "caso de vida e de morte"; "extraordinariamente comum"; "aparente princípio e fim"; "julho-agosto"; "fundos do município"; e o último "raia noroesteâ". Logo se vê o tom de indeterminação na descrição do fato que será narrado. Primeiro, no nível temporal: "aparente princípio e fim, num julho-agosto"; depois, no nível espacial: "nos fundos do município [...] em sua raia noroesteâ". Não só a localização espaço-temporal do fato é indeterminada, mas ainda a sua própria existência e exato conhecimento ("sem que bem se saiba"), sua natureza paradoxal ("extraordinariamente comum") e até mesmo o nome da personagem que o protagonizou, que é incerto ou múltiplo (Pedro Orósio, Pedrão Chãbergo ou Pê-Boi). Diante de toda essa indeterminação ou plurissignificação, o comentário com que o narrador fecha o período, "para dizer com rigor" adquire um tom bastante irônico.

Constatada a indeterminação - e a sua importância segundo o autor - permanece ainda a necessidade de se responder à indagação: ela está a serviço de quê? Da fluidez; do inesperado; da incerteza que é imanente à vida, foi o que me pareceu a princípio. Não determinando com exatidão o fato, este ganha a aura de acontecimento imotivado, ou inapreensível em sua totalidade, desenrolando-se não como consequência do ato humano, mas que antes enforma o homem e o enreda por meio de incontroláveis e contingentes desdobramentos. Ao comentar um dos prefácios de Tutameia, "Sobre a escova e a dúvida", Paulo Rónai alude a essa força que aparentemente perpassa vários momentos da obra do autor: "Possivelmente há em tudo isto uma alusão à reduzida influência de nossa vontade nos acontecimentos, às decorrências totalmente imprevisíveis de nossos atos"."

Vale repetir a proposição: "as coisas 'acontecem', ninguém 'faz' nada, só pensa que faz". A indeterminação parece ser de alguma maneira o elemento decisivo que cria o "princípio de incerteza" imanente ao estatuto do ficcional? Esse parágrafo inicial anunciaria então que as personagens e o universo de "O recado do morro", fadados a se submeterem à força de um destino que não se pode controlar, teriam de ser marcados em sua construção por essa decisiva indeterminação que leva à

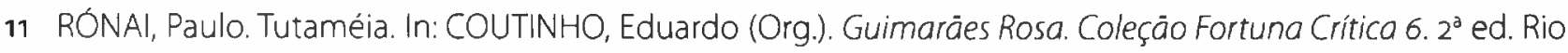
de Janeiro: Civilização Brasileira, 1991, p. 530.

328 - VIOTTI, Fernando Baião. Em busca do indeterminado: Guimarães Rosa... 
suspensão dos significados absolutos. Essa conclusão, no entanto, parece genérica demais para um autor como Guimarães Rosa, cujo texto ficcional assume, em instantes específicos, altíssima função referencial. Os significados ficam muitas vezes em suspenso, mas não são completamente abolidos, é importante frisar.

Os comentários de Rosa nas cartas mostram que não se trata de abrir mão do sentido - proposição que seria a de uma certa literatura contemporânea -, até porque o autor parece querer levar ao leitor um conhecimento específico sobre o homem e o mundo, ainda que em clave alternativa. Nessa medida é difícil situar Rosa num sistema rígido que opõe a arte pela arte - que abdicou de propor mecanismos de representação do real, referindo-se sempre a si própria - a uma outra que aspira a representar o homem e a vida, ainda que transformando ou deformando a base empírica que lhe serve de ponto de partida. As suas proposições - às vezes contraditórias - indicam que o autor resiste a esse tipo de classificação, e, ainda que a obra ficcional não seja o objeto direto de análise deste trabalho, arrisco dizer que sua obra também resiste à rigidez de tais rótulos ou antagonismos radicais, antes se deslocando entre as balizas que esses extremos marcam.

É possível falar de predominância de uma ou outra atitude estética. No tocante às temáticas religiosas, por exemplo, mas ainda noutros casos, como nas referências geográficas às vezes imprecisas, ${ }^{12} \mathrm{o}$ que o autor parece querer evitar é um modelo fechado de representação, deixando em suspenso e indeterminado aquilo que, do contrário, ganharia ares de representação documental. Ao discutir a teoria do efeito estético proposta por Wolfgang Iser, que dedica atenção especial à questão, Gabriele Schwab destaca: "A determinação nos decepciona, afirma Iser, para quem, a indeterminação é que assegura a fluidez, a flexibilidade e consequentemente, a vida". ${ }^{13}$

A concepção não parece distante daquela manifestada por Guimarães Rosa, assim como também não parece novidade em face da mencionada proposição crítica

Antonio Candido já mencionava a questão no ensaio de 1957. Em grandesertao.br, Willi Bolle retoma o assunto, reafirmando as pistas falsas que embaralham o espaço geográfico em que se desenrola o romance. Vide o capítulo "O sertão como forma de pensamento". In: BOLLE, Willi. grandesertao.br. Sāo Paulo: Duas Cidades/ Ed. 34, 2004, p. 47-89.

13 SCHWAB, Gabriele. Se ao menos eu não tivesse de manifestar-me: a estética da negatividade de Wolfgang Iser. In: ROCHA, João Cezar de Castro (Org.). Teoria da ficção: indagaç̧ōes à obra de Wolfgang Iser. Rio de Janeiro: EdUERJ, 1999, p. 45. 
de Antonio Candido. Essa ideia - a "suspensão" do sentido -, que para o crítico é central na realização artística, parece realizar-se para Guimarães Rosa não apenas no conjunto abstrato que é a totalidade de um conto ou romance, mas referida concreta e pontualmente no corpo de seu próprio texto ficcional.

Percebe-se, portanto, que o objetivo final do escritor é justamente não chegar a qualquer explicação final e conclusiva quanto à dimensão ontológica de suas personagens, e que, ao caracterizá-las, aplica estilisticamente o recurso da indeterminação, não como preciosismo gratuito, mas com a finalidade consciente de representar, no nível formal, a própria natureza humana, que é também indeterminada, fluida, instável. Os exemplos das cartas que busquei destacar atestam que esse é um impulso deliberado e elaborado com minúcia, podendo ser creditado na conta dos procedimentos estéticos a que Guimarães Rosa denotava especial distinção.

Também encontramos, contudo, um outro impulso manifesto nas cartas - de sentido contrário - que parece sugerir uma justificativa para o recurso à indeterminação, nunca utilizado arbitrariamente: há algumas coisas que devem ficar indeterminadas, enquanto outras devem ser especificadas e precisadas ao máximo. A indeterminação não pode marcar o texto de modo indiscriminado, ela é instrumento a que o autor recorre às vezes, sempre com finalidades específicas. Essa direção interpretativa parece mais adequada às concepções do autor, fazendo diminuir, assim, o caráter de generalidade que marcaria a busca pelo indeterminado, impulso que, no caso de Rosa, só é possível entender a partir de uma visada dialética.

Justificativas para a indeterminação Para avançar na caracterização e análise da indeterminação como elemento estruturante na visão e prática literária do autor, parece necessário frisar os conceitos articulados neste ensaio. Parti do termo "suspensão", utilizado por Antonio Candido e por Guimarães Rosa, para indicar aquilo que não deve ser elucidado totalmente. Da suspensão passei a abordar a indeterminação, expressão usada por Guimarães Rosa, tomando-a como termo correlato, na medida em que também sugere algo que deve resistir à precisão específica quando for nomeado ou descrito.

Para facilitar a tipificação deste elemento que pode ter muitos nomes e avançar na investigação sobre o tema nas cartas, será necessário recorrer à visada dialética, 
pois o autor que pede aos tradutores a indeterminação, chegando a caracterizá-la como elemento central de sua Weltanschauung, é o mesmo que passara meses debatendo com Harriet de Onís a tradução exata da palavra "cigarra", ou que pedira, também na revisão da tradução de "Duelo": "o termo 'rancho' foi traduzido por 'shack', palavra que vem traduzindo também 'cafua'. Como essas designações aparecem com grande frequência em meus livros, gostaria que as precisássemos" 14

Essa busca pela palavra exata se verifica ainda no primeiro trecho da tradução de Meyer-Clason comentado por Rosa na carta de 11 de novembro de 1959. Tratase de uma tentativa de tradução da primeira página do Grande sertão: veredas: "Pág.1; linha 3... no quintal....im Garten. ('Quintal', não sei se se traduz bem por 'Garten', ou por 'Hof'. Quintal é um terreno em geral grande, atrás da casa, englobando horta, jardim, pomar, pátio e partes baldias ou incultas.)"15 E ainda, cinco anos mais tarde, ao comentar com Meyer-Clason amostras de tradução de "Dão-lalalão": "Não sei se 'verrosteten' fica bem para 'oxidado', aqui. (Não é enferrujado com o tempo.) Diz-se 'oxidado' de um revólver já fabricado assim, com um tipo de metal especial, de cor escura. (Rogo indagar, verificar, perguntar em casa que vende armas.)"16

Ao tratar do tipo humano predominante no Grande sertão: veredas, o jagunço, Antonio Candido observa como o livro "é meticulosamente plantado na realidade física, histórica e social do norte de Minas, que ele revelou à sensibilidade do leitor brasileiro como nova província, antes não elevada à categoria de objeto estético"."7 Para apontar a singularidade do jagunço de Guimarães Rosa, Antonio Candido mostra como esse jagunço vem no livro caracterizado com minúcia documental, que se espraia para os outros planos concretos de seu universo narrativo; a terra, os bichos e as plantas, sempre nomeados com exatidão.

Tal exatidão, entretanto, vinha acompanhada paradoxalmente por esse outro impulso, que era a busca pela indeterminação. Cabe retomar que o autor a destaca como

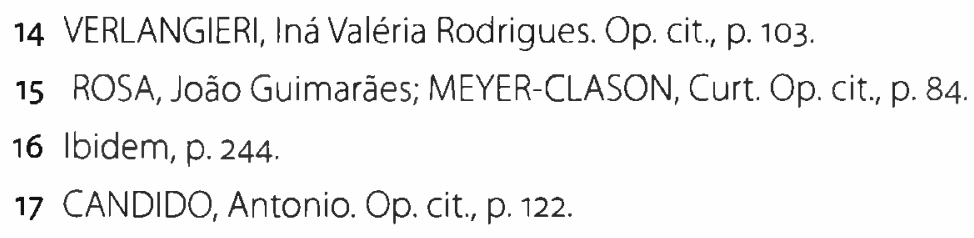


meio de expressão de sua visão de mundo, na qual "as coisas 'acontecem', ninguém 'faz' nada, só pensa que faz". Numa tentativa de desdobrar as significações possíveis para a assertiva, tornando-a menos oblíqua, trabalhei na seção anterior com a noção de que, para o autor, o homem está enredado sempre por forças misteriosas que desconhece - em muito mais mistérios do que supõe, para utilizar o repisado clichê shakespeariano. Na seção anterior a busca da indeterminação me parece ter ficado caracterizada como procedimento genérico, de certa maneira imanente ao texto literário, algo que já se pode depreender partindo principalmente das citações de Antonio Candido e Wolfgang Iser - ainda que o primeiro fale especificamente de Grande sertão: veredas e o segundo trate da natureza geral de qualquer texto literário.

As cartas parecem oferecer, entretanto, pistas indicativas de qual seria a especificidade - as raízes, impulsos e justificativas - por trás da busca pela indeterminação ou suspensão. Uma delas é a carta-resposta ao primeiro rol de dúvidas enviado por Edoardo Bizzarri quanto à tradução de Corpo de baile, com a data de 11 de outubro de 1963:

vejo que coisa terrível deve ser traduzir o livro! Tanto sertão, tanta diabrura, tanto engurgitamento. Tinha-me esquecido do texto. O que deve aumentar a dor-de-cabeça do tradutor é que: o concreto é exótico e mal conhecido; e, o resto, que devia ser brando e compensador, são vaguezas intencionais, personagens e autor querendo subir à poesia e à metafísica, juntas, ou, com uma e outra como asas, ascender a incapturáveis planos místicos. Deus te defenda. ${ }^{18}$

De um lado, o concreto: "exótico e mal conhecido". de outro o resto, por pressuposto, o abstrato: "vaguezas intencionais". A separação que propõe o autor facilita o entendimento dos dois impulsos em certa medida antagônicos que destaquei em suas cartas. Ora, não é de espantar que, para reger e construir um universo ficcional balizado entre linhas desta natureza, o autor tenha de se valer de atitudes diferentes: para o primeiro caso, a precisão; para o segundo, a indeterminação. Rosa sabia que, para concretizar no plano ficcional um "exótico e mal conhecido" universo sertanejo, base e cenário para a obra, seria necessária a explicação

18 ROSA, João Guimarães; BIZZARRI, Edoardo. Op. cit., p. 37-8. 
documental mais minuciosa, que só mesmo um escritor pesquisador do sertão como ele seria capaz de fornecer a contento. Por outro lado, o seu contraponto abstrato, "vaguezas intencionais, personagens e autor querendo subir à poesia e à metafísica", só poderia sustentar-se no plano ficcional a partir de uma indeterminação que lhe é indispensável, já que, do contrário, o texto seria ou lição de estilística ou proselitismo religioso, perdendo o estatuto de ficcional que o marca tão intensamente.

Assim, aparecem comentados os expedientes distintos do autor que quer ora lançar luz sobre um concreto "mal-conhecido", ora transformar pela imprecisão ou mistura, abstrações subjetivas que - ao contrário - estão exaustivamente descritas tanto no âmbito literário estrito, quanto no campo dos discursos filosóficos ou religiosos.

Ao falar de "vaguezas intencionais", o autor confirma um procedimento - ou pelo menos uma tendência de concepção da obra - próprio de uma temática específica, e sugere aos tradutores que o secundem, como veremos em outras passagens. A indeterminação deve ser buscada com um propósito bem definido, e é uma especificidade temática que a justifica. Quando surge em primeiro plano a metafísica, a reflexão sobre a condição humana, o mistério e, consequentemente, a poesia que daí deriva, o tom de indeterminação deve predominar no cerne do discurso - modo de concretizar formalmente - ou se se preferir literariamente - a "vagueza" que permeia a visão de mundo do autor.

Numa sugestão feita a Harriet de Onís acerca de trecho da tradução de "O burrinho pedrês", há uma nova menção ao procedimento, com uma explicação pormenorizada quanto à justificativa para se recorrer a ele neste caso. Rosa considera "pesado", "longo", "muito rigidamente expositivo e lógico" o trecho "was seeking himself out, discovering himself, finding the essence of his being. Propõe "algo assim: was surely and perhaps seeking himself out, finding some essence of his being...., justificando-se: "funcionalmente, é para o leitor não poder entender mesmo, pela lógica estreita do common-sense, o que se refere às vaguezas misteriosas da vida, do que é apenas para se sentir por sugestão, apoiada na poesia do intencionalmente confuso e na força oblíqua do humour..." 19

Ou seja, aquilo que se refere às "vaguezas misteriosas da vida" deve conter sempre algo de oblíquo, de indeterminado, como o "surely and perhaps" postos lado a lado, 
oxímoro que lembra tanto o "excepcionalmente comum" do primeiro parágrafo de "O recado do morro" para o qual o autor pede atenção redobrada ao tradutor Curt Meyer-Clason. Talvez o restante do trecho seja ainda mais esclarecedor, ao falar de "sentir por sugestão"; "intencionalmente confuso" e "força oblíqua do humour" Com essas expressões, fica caracterizado um modus escolhido pelo autor para tratar as questões metafísicas ou filosóficas, sem propor a transposição ao plano literário de discursos logicamente organizados, mas antes desmontando e reorganizando tais discursos, muitas vezes utilizados apenas como "células temáticas".20

Outro comentário importante de Rosa que vai nessa direção é o que encerra a carta de 19 de novembro de 1963 a Edoardo Bizzarri, sanando dúvidas sobre "Dãolalalão" e "O recado do morro":

Mas, no ferver do assunto, estou-me alongando demais, sem precisão, e Você já tem trabalho demais com o diabo do livro, que, como Você vê, também foi um pouco febrilmente tentado arrancar de dois caos: um externo, o sertão primitivo e mágico; o outro eu, o seu Guimarães Rosa, mesmo, que abraça Você, grata e afetuosamente. ${ }^{21}$

Aqui o autor aprofunda a dicotomia, ao mesmo tempo em que fornece novo subsídio para sua compreensão. Rosa acrescenta à caracterização de seu sertão "exótico e mal conhecido", os adjetivos "primitivo" e "mágico". Esse sertão continua sendo o espaço concreto, aqui chamado de espaço "externo", e aquilo que antes era "o resto" ou seja, o "não-concreto"; o "abstrato" por pressuposto agora é o espaço interior, a interioridade do criador, que não é difícil associar "às vaguezas intencionais" do trecho anterior.

Rosa novamente usa duas categorias para distinguir o tipo de matérias-primas básicas de que se vale para a construção da obra, mas aqui, ao invés de operar a distinção entre concreto e abstrato, aplica "mundo externo" e "mundo interno", sendo que este último coincide, nesse caso, com sua própria subjetividade.

Fazendo uma associação entre as duas explicações, tão semelhantes e separadas pelo intervalo de pouco mais de um mês, não é difícil estabelecer os paralelos entre

20 Expressão de Rosa em carta a Bizzarri.
21 ROSA, João Guimarães; BIZZARRI, Edoardo. Op. cit., p. 87.

334 - VIOTTI, Fernando Baião. Em busca do indeterminado: Guimarães Rosa... 
concreto e mundo externo de um lado e abstrato e mundo interior de outro. Nesta segunda citação, mais do que a distinção entre dois planos que mais ou menos repete a da carta anterior, chamou-me a atenção a marca comum com a qual o autor caracteriza esses dois mundos, o exterior e o interior: a desordem caótica que os governa. Ainda que caracterizados por este traço comum, ambos pedem, entretanto, tratamentos distintos. Enquanto o caos do mundo externo, concreto, deve ser ordenado através da descrição pormenorizada de sua natureza exótica, o mundo interior pede uma caracterização por meio de sugestões, contraditória e paradoxal, realizada pela própria organização formal do discurso literário, que mimetiza em sua estrutura a natureza caótica humana a que se refere.

Isto não quer dizer que o autor tentasse construir um retrato exato do sertão através do detalhamento daquilo que, na obra, tem referência mais direta na realidade, mas apenas que, ao tratar dessa matéria concreta, da "massa da documentação" como ele mesmo a chamou, ${ }^{22}$ esse impulso de precisar as coisas e seu nome fosse predominante, ainda que o próprio autor, em algum momento, optasse por deixar também indeterminado algo que se referisse a essa matéria concreta. ${ }^{23}$

$\mathrm{Na}$ outra vertente, os comentários de Rosa deixam claro o predomínio do vago e indeterminado, rejeitando qualquer explicação lógica e absoluta quando o assunto é o metafísico, o "suprassensível" ou mesmo as subjetividades da natureza humana, como a carta a Bizzarri sugere. Essa subjetividade, comparecendo na obra de modo peculiar, é referida diretamente nessa carta - o que obviamente não se repete na obra - por via de um "eu, o seu Guimarães Rosa", como se o autor estivesse falando de si num plano confessional, algo muito distante de toda a sua literatura. Não é o caso de

22 Na carta de 25 de novembro de 1963 a Edoardo Bizzarri, entre comentários gerais sobre a concepção de Corpo de baile, Rosa diz ao tradutor: "o sertão é de uma autenticidade total. Quando eu escrevi o livro, eu vinha de lá, dominado pela vida e paisagem sertanejas. Por isto mesmo, acho, hoje, que há nele certo exagero na massa da documentaçāo." (Ibidem, p. 90).

23 Ao esclarecer a Bizzarri termos duvidosos de "O recado do morro", há dois exemplos desse tipo: primeiro: [pergunta de Bizzarri]: "quadradāo (qual a extensāo aproximativa?); [resposta de Rosa]: quadra-de-sesmaria. Talvez, porém, o melhor seja deixar indeterminado: um grande trecho de pastagens. Segundo: [pergunta de Bizzarri] "joão" (qual das muitas plantas "joão" etc.?); [resposta de Rosa]: Impreciso, indeterminado (usado pelo pitoresco do nome.) Mas bem pode ser o mentastro (Argetum conysoides, L.): Composta herbácea e rústica. Espécie pilosa e aromática". (Ibidem, p. 71-72). 
se levar a ferro e fogo essas explicações do autor. Não se pode esquecer que o que temos aqui são cartas, nas quais é muito menor a preocupação com o termo técnico, específico, que seria de esperar num ensaio crítico. Insisto na tese de que o referido aqui é uma subjetividade genérica - aquilo que é abstrato, em suma - que o escritor sente, conhece e exprime, e que pode ou não encontrar eco em sua subjetividade pessoal.

A temática é inescapável, perpassando de forma recorrente tanto o presente trabalho quanto as cartas, chegando o escritor a garantir a Bizzarri uma assertiva ao mesmo tempo reveladora e oblíqua: "Os livros são como eu sou". Constatado o problema, resta tentar alcançar a sua particularidade. A discussão sobre o quanto de expressão pessoal está vazado na obra de arte é tão antiga quanto a própria arte, e parece que continuará irresolvida por um bom tempo. Alfredo Bosi faz um esclarecedor apanhado do tema em Reflexões sobre a arte, em que mostra como "as formas expressivas são geradas no bojo de uma intencionalidade que as torna momento integrante ou resultante do pathos" ou, ainda, do "pressuposto geral da correspondência que prende as formas expressivas aos movimentos da alma e do espírito".24 Não se trata, como se vê, de transpor sem escalas os impulsos que animam uma subjetividade para o plano expressivo, mas de uma "dialética entre força interior e expressão"25 da qual Guimarães Rosa parecia bem consciente.

A subjetividade pode ser expressa de distintas maneiras, excluído logo o derramamento sentimental romântico que o termo a princípio sugere. No caso específico de Guimarães Rosa, essa subjetividade aludida pelo autor parece corresponder mais a uma visão-de-mundo fatalmente filtrada na variada gama de conhecimentos estéticos, filosóficos e religiosos - sem desprezar os obtidos da observação empírica tanto do sertão, quanto do espaço cosmopolita urbano - acumulados pelo autor no decorrer de sua vida. Poderíamos dizer que essa expressão é quase a de uma "subjetividade cultural" que o autor formou como processo de preparação para a concepção de sua obra.

Seria este o "caos interior" a que se refere, matéria-prima talvez principal para a concepção da obra, um amálgama no qual cabiam ingredientes dos mais diversos, sempre medidos com o cuidado necessário para que um ou outro não

24 BOSI, Alfredo. Reflexões sobre a arte. $2^{2}$ ed. São Paulo: Ática, 1986, p. 52-3.

25 Ibidem, p. 65.

336 - VIOTTI, Fernando Baião. Em busca do indeterminado: Guimarães Rosa... 
sobressaíssem acima dos demais, resultando na mistura sofisticada que se detecta nas obras em vários níveis, e às quais o autor alude frequentemente na correspondência, como nesta carta a Bizzarri: "Voltando ao 'Dão-lalalão', isto é, aos curtos trechos em que assinalei as 'alusões' dantescas, apocalípticas e cântico-dos-canticáveis. (ALIÁs, é apenas nessa novela que o autor recorreu a isso), etc, etc, etc. sup-para-citações, só células temáticas" ${ }^{26}$

Parafraseando Rosa em termos mais explicativos, as "alusões" da obra a textos da tradição literária ou filosófico-religiosos, funcionam como espécie de embriōes apenas, para desenvolvimento no plano literário das questões metafísicas que tanto lhe interessavam, constituindo parte formativa importante da subjetividade que ele próprio acusa como matéria-prima para as obras.

Tal subjetividade foi forjada no conhecimento objetivo da mais variada tradição cultural, predominantemente ocidental, mas que eventualmente podia incluir elementos orientais. $\mathrm{O}$ arquivo do escritor, depositado no Instituto de Estudos Brasileiros, da Universidade de São Paulo, é a prova cabal desta preparação a que o escritor se dedicou para a construção da obra. A variada gama de assuntos que os seus cadernos e cadernetas abrangem, e mesmo o ecletismo das citações de suas cartas, atesta que a sua vida - ou sua subjetividade, se quisermos manter uma coerência taxonômica - constituía-se em grande parte da bagagem cultural que adquiriu no decorrer da vida.

Vida que, então, na explosão criadora que foi Grande sertão: veredas e Corpo de baile, torna-se literatura. Nesse caso não a vida em sua dimensão cotidiana, mais frugal e ramerrã, que também pode tornar-se grande literatura - como o prova a poesia de Manuel Bandeira -, mas a vida que aspira a subir "às alturas do espírito", que quer ser sublime, intelectualizada, organizada em sua assustadora variedade por um princípio de indeterminação que é marcante no sujeito e está vazado na obra.

Fernando Baião Viotti é mestre em Estudos Literários pela Universidade Federal de Minas Gerais.

26 ROSA, João Guimarães; BIZZARRI, Edoardo. Op. cit., p. 88. 